\title{
A INFORMAÇÃO COMO PRODUTO E A PROTEÇÃO DO CONSUMIDOR NA SOCIEDADE DA INFORMAÇÃO: ESTUDO DE CASO
}

\section{INFORMATION AS A PRODUCT AND CONSUMER PROTECTION IN THE INFORMATION SOCIETY: A CASE STUDY}

\begin{abstract}
Roger da SiLVA MOREIRA SOARES
Mestrando em Direito da Sociedade da Informação pelo Centro Universitário das Faculdades Metropolitanas Unidas (FMU/SP). Auxiliar voluntário de ensino na FMU/SP. Advogado. São Paulo, SP, Brasil.
\end{abstract}

rsmsoares@gmail.com

MARCO ANTÔNIO BARBOSA

Bacharel, Mestre e Doutor em Direito pela Universidade de São Paulo (USP), professor, pesquisador e orientador do Programa de Mestrado em Direito da Sociedade da Informação e do Curso de Graduação em Direito do Centro Universitário das Faculdades Metropolitanas Unidas (FMU/SP). São Paulo, SP, Brasil.

marco.barbosa@fmu.br

\section{RESUMO}

Analisa-se o lado econômico da informação e sua importância no atual cenário social, chamado de sociedade informacional. A informação, devidamente trabalhada e administrada, se apresenta como um bem de alto valor para a sociedade e, principalmente, para os grupos econômicos, que extraem lucros consideráveis. Entretanto, a administração de tais informações com intuito de obtenção ou otimização dos lucros, por vezes, caracteriza violação de direitos básicos dos consumidores, demandando a adoção de postura de proteção a tais personagens que, muitas das vezes, não têm consciência das violações de seus direitos. Analisa-se igualmente um caso concreto, onde é possível se observar a economicidade da informação e a capacidade de gerar dano ao consumidor, qual seja, a implantação, pela ANVISA Agência Nacional de Vigilância Sanitária, do sistema de rastreabilidade de medicamentos.

Palavras-chave: ANVISA; Intimidade; Propriedade; Rastreabilidade; Sociedade da informação.

\begin{abstract}
This study analyzes the economics of information and its importance in the current social scenario, called the information society. Information, properly processed and managed, presents itself as a very high value good to society and especially to the economic groups that draw considerable profits. However, the administration of such information with the intention of obtaining or optimizing profits sometimes characterizes violation of basic consumer rights, demanding the adoption of protective postures to these people who often are unaware of the violations of their rights. The research also analyzes one case where it is possible to observe the economic efficiency of information and the ability to generate harm to the consumer, which is the establishment of the medicine traceability system, by ANVISA - National Health Surveillance Agency.
\end{abstract}

Keywords: ANVISA; Intimacy; Property; Traceability; Information society. 


\section{(R)

\section{SUMÁRIO}

INTRODUÇAO; 1 A SOCIEDADE DA INFORMAÇÃO; 2 O ASPECTO ECONÔMICO DA INFORMAÇÃO; 3 A PROTEÇÃO DO CONSUMIDOR NA SOCIEDADE DA INFORMAÇÃO. 4 ESTUDO DE CASO: RESOLUÇÃO RDC N ${ }^{\circ}$ 54/2013 E IN N 6/2014, DA ANVISA, EM CUMPRIMENTO À LEI N 11.903, DE 14 DE JANEIRO DE 2009; CONCLUSÃO; REFERÊNCIAS.

\section{INTRODUÇÃO}

O presente artigo trata da informação como produto, analisando o seu valor econômico no âmbito da sociedade informacional e de como a utilização de informações como produto poderá ocasionar violações a direitos garantidos constitucionalmente, principalmente ao consumidor, sem mesmo que este tenha conhecimento de que algumas informações suas, com proteção constitucional, possam estar sendo utilizadas para fins comerciais, otimizando operações empresariais e maximizando lucros de grandes corporações.

Analisa-se a sociedade da informação, a revolução tecnológica que permitiu acesso à informação a um público cada vez maior, de forma ágil e quase que instantânea. A tecnologia, além de permitir a troca rápida de informações e de reduzir distâncias entre os interlocutores, também permite armazenar e gerenciar essas mesmas informações, agregando-lhes um grande valor quando devidamente tratada. Isso provoca a supervalorização da informação que, tratada como mercadoria, supera, muitas vezes, até mesmo o próprio patrimônio físico de muitas empresas. Informações como marcas mundialmente reconhecidas, operações de logística e venda, características de consumidores de determinada região, a exemplo de seus gostos, costumes e hábitos possuem grande valor agregado no mundo empresarial, pois permitem às empresas identificar onde e com qual público seu empreendimento terá mais sucesso. Entretanto, informações sensíveis e íntimas dos consumidores poderão, em princípio de forma indevida, ser utilizadas em operações empresariais, cujos objetivos visam otimizar lucros de tais corporações.

No presente trabalho, a sociedade da informação e a proteção do consumidor são analisadas mediante estudo de caso concreto, qual seja, o Sistema Nacional de Controle de Medicamentos, instituído pela Lei $n^{\circ} 11.903$, de 14 de janeiro de 2009, regulamentada pela Resolução da Diretoria Colegiada $n^{\circ}$ 54, de 10 de dezembro de 2013 e pela Instrução Normativa $n^{\circ}$ 6, de 18 de agosto de 2014, da ANVISA - Agência Nacional de Vigilância Sanitária. 
Extrai-se das normas supracitadas as regras de rastreabilidade de medicamentos, desde seu nascedouro no estabelecimento industrial do laboratório farmacêutico até a entrega ao consumidor final, identificando-se todos os elos da operação, até mesmo o profissional de saúde que prescreveu o medicamento e o consumidor (artigo $3^{\circ}$, parágrafo $1^{\circ}$, incisos VI e VIII, da Lei $\mathrm{n}^{\circ} 11.903$, de 14 de janeiro de 2009), além de toda operação de logística dos demais elos da cadeia de fornecimento de medicamentos. A Instrução Normativa $\mathrm{n}^{\circ}$ 6, de 18 de agosto de 2014, da ANVISA, em seu artigo $4^{\circ}$, estabelece que tais informações devem estar concentradas junto ao detentor do registro do produto, ou seja, informações tais como operações empresariais (logística), informações relativas a determinado médico, odontólogo ou veterinário, além de informações sobre o consumidor estarão de posse de uma pessoa jurídica com fins lucrativos, tudo sob a chancela da ANVISA - Agência Nacional de Vigilância Sanitária, como se verá.

É certo que tais informações podem auxiliar no combate a fraudes e falsificações de medicamentos, bem como inviabilizar o desvio de mercadorias e roubos de carga, além de permitir ao consumidor, no momento da aquisição do medicamento, identificar toda a sua trajetória até determinada drogaria. Entretanto, o que se questiona aqui é a concentração de tais informações não nas mãos da própria ANVISA - Agência Nacional de Vigilância Sanitária, órgão responsável pelo controle de medicamentos no Brasil, mas sim de corporações nacionais e multinacionais, cujo objetivo de seus negócios é a obtenção de lucro.

\section{A SOCIEDADE DA INFORMAÇÃO}

Para se ter ideia sobre a sociedade da informação ou sociedade informacional é necessário entender as principais e contundentes revoluções pelas quais o mundo passou desde a revolução agrícola, passando pela industrial até se chegar na informacional, na qual se vive atualmente. $\mathrm{Na}$ sociedade agrícola o poder econômico era diretamente vinculado à terra por meio da agricultura que subordinava todos os demais meios de produção com amplos reflexos sociais e políticos. Posteriormente, o advento das máquinas caracterizou a revolução industrial, o poder econômico pela máquina, o que "possibilitou a transformação da agricultura, da pecuária, do extrativismo, do comércio e, ainda, acarretou o surgimento da empresa moderna, modificando consideravelmente as relações socioeconômicas existentes"1.

\footnotetext{
${ }^{1}$ LISBOA, Roberto Senise. Direito na sociedade da informação. Revista dos Tribunais, ano 95, vol.847, maio 2006, p.79.
} 
A industrialização ocorre quando as formas intensivas de energia não-animal são aplicadas às técnicas de produção em massa. Como todas as inovações, esta começou vagarosamente, quando as máquinas a vapor foram aproveitadas nos grandes teares mecânicos para produzirem tecidos de algodão numa escala nunca antes imaginada. As máquinas a vapor, movidas a carvão, logo são aplicadas em outros setores, como o ferroviário, nas locomotivas, o da navegação, o da produção em massa de derivados de metal, principalmente armas, espingardas e canhões. Num século, o mundo europeu estava transformado, e essa incrível capacidade produtiva modificou não apenas os países industrializados, mas também todas as outras nações do mundo².

Por sua vez, a revolução informacional corresponde ao poder econômico pelo domínio da informação, conjugado ao aprimoramento dos meios de comunicação, possibilitando o acesso coletivizado da informação e, ainda, a interoperabilidade na rede, permitindo os desdobramentos sobre as próprias transformações outrora trazidas pelas revoluções industrial e agrícola, incrementando as tecnologias existentes e criando novas, com inevitáveis repercussões socioeconômicas.

Roberto Senise Lisboa esclarece que:

Pode-se afirmar que o estabelecimento da fábrica trouxe repercussões notáveis sobre a produção dos bens e a sua distribuição pelo comércio. De forma similar, a revolução informacional trouxe o aprimoramento dos meios de comunicação, possibilitando o acesso coletivizado da informação e, ainda, a interoperabilidade na rede ${ }^{3}$.

Sociedade da informação é aquela cujo desenvolvimento está baseado em dados, informação e conhecimento, ou seja, calcada em bens imateriais, marcada pelo avanço tecnológico, passando a fornecer as bases da economia em geral. Argumenta, ainda, Siqueira Jr., que o conceito de sociedade da informação é amplo, não se limitando ao aspecto tecnológico, eis que também inclui o tratamento e transmissão da informação, o que lhe atribui valor econômico ${ }^{4}$.

0 termo sociedade da informação surgiu pela voz do então Presidente da Comissão Europeia, Jacques Delors, por ocasião do Conselho Europeu (1993), ao

\footnotetext{
${ }^{2}$ SHIRLEY, Robert Weaver. Antropologia Jurídica. São Paulo: Saraiva, 1987, p.73.

3 LISBOA, Roberto Senise. Direito na sociedade da informação. Revista dos Tribunais, ano 95, vol.847, maio 2006, p.79.

${ }^{4}$ SIQUEIRA JUNIOR, Paulo Hamilton. A nova ordem constitucional. In: PAESANI, Liliana Minardi (Coord.). Direito na sociedade da informação III. São Paulo: Atlas, 2013, p.203.
} 
lançar pela primeira vez a ideia das infraestruturas da informação. A sociedade da informação é constituída em tecnologias de informação e comunicação que envolvem a aquisição, o armazenamento, o processamento e a distribuição da informação por meios eletrônicos, como rádio, televisão, telefone e computadores, entre outros. Essas tecnologias não transformam a sociedade por si sós, mas são utilizadas pelas pessoas em seus contextos sociais, que tem reflexos na sociedade local e global, surgindo assim a sociedade da informação ${ }^{5}$.

Cita-se, por oportuno, a doutrina de Irineu Francisco Barreto Júnior.

A sociedade contemporânea atravessa uma verdadeira revolução digital em que são dissolvidas as fronteiras entre telecomunicações, meios de comunicação de massa e informática. Convencionou-se nomear esse novo ciclo histórico de Sociedade da Informação, cuja principal marca é o surgimento de complexas redes profissionais e tecnológicas voltadas à produção e ao uso de informação, que alcançam ainda sua distribuição através do mercado, bem como as formas de utilização desse bem para gerar conhecimento e riqueza ${ }^{6}$.

Roberto Senise Lisboa identifica os principais efeitos da revolução informacional, elencando a transnacionalização e o surgimento de blocos econômicos, esclarecendo que "há um movimento socioeconômico de integração mundial e contrário ao estabelecimento de um Estado superior, o que leva aos inevitáveis conflitos de interesses entre Estados e macro empresas e seus lugares de atuação"; o e-commerce, gerando questões sobre problemas de atribuição de autoria de documentos eletrônicos e assinatura digital, validade de documento original e copiado, proteção dos direitos intelectuais, proteção dos direitos de propriedade na web, oferta e publicidade eletrônica, contratos eletrônicos e a proteção do consumidor; a economicidade da informação; a formação de bancos de dados; a transferência eletrônica de dados; e o estabelecimento de normas comunitárias, “com vistas a uma uniformização do tratamento legislativo sobre a matéria" ${ }^{7}$.

É certo afirmar que o acesso à informação é um direito fundamental, garantido pela Constituição Federal/88, em especial pelos incisos XIV e XXXIII do artigo $5^{\circ}$. Entretanto, analisase neste trabalho a informação como produto, o seu valor econômico e a sua utilização no mercado capitalista.

\footnotetext{
${ }^{5}$ SIQUEIRA JUNIOR, Paulo Hamilton. A nova ordem constitucional. In: PAESANI, Liliana Minardi (Coord.). Direito na sociedade da informação III. São Paulo: Atlas, 2013, p.203

${ }^{6}$ BARRETO JÚNIOR, Irineu Francisco. Atualidade do conceito de sociedade da informação para pesquisa jurídica. In: PAESANI, Liliana Minardi (Coord.). Direito na sociedade da informação. São Paulo: Atlas, 2007, p.62.

7 LISBOA, Roberto Senise. Direito na sociedade da informação. Revista dos Tribunais, ano 95, vol.847, maio 2006, p.84-85.
} 


\section{每

\section{O ASPECTO ECONÔMICO DA INFORMAÇÃO}

A sociedade informacional não se resume somente ao uso da tecnologia para gerar e transmitir a informação, ao uso da internet, rádio, televisão ou outros meios de propagação da informação por meios tecnológicos, mas identifica o poder emanado ou gerado pela informação. A informação devidamente tratada gera conhecimento, passando a ostentar um aspecto econômico. Peter Burke trata da ideia da informação como produto e observa seu aspecto econômico:

Uma das razões para se afirmar que vivemos numa sociedade da informação é que a produção e venda de informações contribui de maneira considerável para as economias mais desenvolvidas. Alguns economistas norte-americanos já tinham chegado a essa conclusão há algum tempo. Na década de 1960, um deles argumentava que seus colegas tinham negligenciado 'os aspectos mercantis do conhecimento' e descrevia as máquinas como 'conhecimento congelado', sugerindo que o desenvolvimento econômico era 'essencialmente um processo de conhecimento'. Quase ao mesmo tempo, outro economista publicava um estudo em forma de livro sobre o conhecimento como produto, considerando seus estoques, custos e preços. Em época mais recente, ocorre uma inundação de livros e artigos sobre a indústria da informação: o marketing da informação, os serviços de informação e a administração da informação ${ }^{8}$.

Manuel Castells sustenta que a revolução tecnológica foi moldada pelos interesses do capitalismo avançado:

A revolução da tecnologia da informação foi essencial para a implementação de um importante processo de reestruturação do sistema capitalista da década de 1980. No processo, o desenvolvimento e as manifestações dessa revolução tecnológica foram moldados pelas lógicas e interesses do capitalismo avançado, sem se limitarem às expressões desses interesses ${ }^{9}$.

A economia do conhecimento, segundo Roberto Senise Lisboa ${ }^{10}$, se sustenta em 3 (três) pilares, quais sejam, o conhecimento impregna tudo o que se compra, se vende ou se produz; os ativos do conhecimento passaram a ser mais importantes para as empresas do que os ativos

\footnotetext{
${ }^{8}$ BURKE, Peter. Uma História Social do Conhecimento: de Gutenberg a Diderot. Rio de Janeiro: Jorge Zahar, 2003, p.136.

${ }^{9}$ CASTELLS, Manuel. A sociedade em rede, vol.1, 8a ed., São Paulo: Paz e Terra, 1999, p. 50.

${ }^{10}$ LISBOA, Roberto Senise. Direito na sociedade da informação. Revista dos Tribunais, ano 95, vol.847, maio 2006, p. 86.
} 
financeiros e físicos; e prosperar na nova economia e explorar esses novos ativos significa a maior utilização de novas técnicas de gestão, novas tecnologias e novas estratégias. Cita-se, ainda, Liliana Minardi Paesani, para quem a informação, pura e simples, não possuiria um valor agregado, sendo necessário o tratamento de tais informações, assim, gerando conhecimento:

\begin{abstract}
A informação, graças à difusão do computador, transformou-se numa mercadoria, uma coleta de dados registrados sob a forma de impulsos magnéticos. Considerase não só o conteúdo, mas também a forma, que é mensurável com absoluta precisão em termos de custo de produção e de valor de mercado. Dessa maneira, a informação transforma-se em nova matéria-prima, pertencente ao gênero especial dos bens imateriais. A organização produtiva transforma-se de unidade de tratamento de materiais em unidade de tratamento de informações. A informação, para poder ser valorada e valorizada, é submetida a tratamentos sofisticados. Pode ser guardada, manipulada como um objeto, cedida, ou até subtraída ilicitamente ${ }^{11}$.
\end{abstract}

Pode-se citar um dado que reflete a importância da informação no mundo capitalista atual, qual seja, o comércio eletrônico, onde informações sobre consumidores, seus gostos, costumes e práticas são compiladas, estudadas, transformadas em estatísticas e posteriormente o marketing agressivo é a estes direcionados, de forma matemática, científica, disparando bombardeios de propagandas dirigidas, direcionadas, o que justifica o sucesso econômico do comércio digital.

Sendo certo afirmar que revolução industrial aperfeiçoou e melhorou as técnicas e produção agrícola, alavancando a produção no campo, o mesmo pode-se dizer da revolução informacional em relação à revolução industrial. Se a revolução industrial permitiu a implantação de uma linha de produção, substituindo o trabalho de muitos trabalhadores por algumas máquinas, gerando redução de custo e diminuição no tempo de produção, fazendo com que mais e mais produtos fossem postos no mercado de consumo, a revolução informacional permitiu que essa avalanche de mercadorias fosse direcionadas para públicos alvos e específicos, fazendo surgir consumidores para a produção ora existente, gerando o hiperconsumo, o consumo de massa.

Algumas estatísticas são criadas com base no perfil de cada cidadão, ora classificado por gênero, idade, profissão, localidade onde vive e hábitos, passando tais informações a possuírem considerável valor agregado. Não basta, no atual cenário econômico, possuir os meios de produção e a matéria prima, se não for possível identificar onde os produtos que se tem a

\footnotetext{
${ }^{11}$ PAESANI, Liliana Minardi. Direito de informática, 10ª ed., São Paulo: Atlas, 2015, p.10.
} 
oferecer melhor poderão ser consumidos, se não for possível identificar onde está o maior e melhor mercado consumidor para estes. O gerenciamento de tais informações, gerando conhecimento, é refletido no sucesso do e-commerce, conforme dados expostos por Adalberto Simão Filho.

Em crescimento constante e sucessivo encontra-se o comércio eletrônico desenvolvido por esses estabelecimentos digitais ou por qualquer outro meio eletrônico. Segundo levantamento feito pelo eMarketer, instituto especializado em pesquisas de mercado, o comércio eletrônico deveria dobrar em cinco ano, passando de US\$ 9,58 bilhões em 2011 para US\$ 17,30 bilhões em 2016. Todavia, acabou por se expandir, somente no ano de 2012 em cerca de $29 \%$, gerando um movimento de R\$24,12 bilhões, segundo relatório da ABComm - Associação Brasileira de Comércio Eletrônico ${ }^{12}$.

O capitalismo se valeu de informações devidamente tratadas, estratégicas, para então educar o consumidor, fazendo surgir a sociedade do hiperconsumo, como alerta Gilles Lipovetsky.

O capitalismo de consumo não nasceu mecanicamente de técnicas industriais capazes de produzir em grandes séries mercadorias padronizadas. Ele é também uma construção cultural e social que requereu a 'educação' dos consumidores ao mesmo tempo que o espírito visionário de empreendedores criativos, a 'mão visível dos gestores' ${ }^{13}$.

A revolução informacional proporcionou mudanças no comportamento empresarial, não podendo se afirmar que tal revolução, no campo empresarial, é boa ou ruim. Empresas surgiram e outras encerraram suas atividades, por não conseguirem acompanhar o desenvolvimento tecnológico, sendo engolidas pela concorrência. O patrimônio convencional das empresas não desaparecerá (capital físico e financeiro), mas é indiscutível que a gestão do conhecimento cada vez mais vem ganhando relevância no mundo corporativo, vindo, para algumas, a se tornar seu principal ativo, eis que possibilitarão diferenciarem-se dos seus concorrentes.

O capital intelectual se constitui em um dos tópicos mais importantes do mundo negocial da atualidade, ao lado da gestão do conhecimento. Percebeu-se, afinal, que os ativos tangíveis das organizações - dinheiro, terrenos e prédios,

12 SIMÃO FILHO, Adalberto. Estabelecimento empresarial digital: natureza, elementos, atributos e valoração. In: PAESANI, Liliana Minardi (Coord.). Direito na sociedade da informação III. São Paulo: Atlas, 2013, p.160.

13 LIPOVETSKY, Gilles. A felicidade paradoxal: Ensaio sobre a sociedade de hiperconsumo. São Paulo: Companhia das Letras, 2007, p. 28. 
instalações, equipamentos e outros itens do balanço patrimonial - são muito menos valiosos que os ativos intangíveis - patentes, direitos autorais, bens da era da informação (como bancos de dados e softwares), e, ainda, capacidades, culturas, habilidades etc. ${ }^{14}$.

Assim, a informação tratada se apresenta como importante insumo na logística empresarial, otimizando a atividade empresarial, melhorando a operacionalização, reduzindo custos e "turbinando" os lucros.

\section{A PROTEÇÃO DO CONSUMIDOR NA SOCIEDADE DA INFORMAÇÃO}

A revolução informacional obtida com o estabelecimento da sociedade em rede deve ser acompanhada por elementos técnicos e comerciais que regulem atividades de gestão do conhecimento compatíveis com o desenvolvimento econômico que o mercado necessita. Entretanto, da mesma forma, o desenvolvimento jurídico deve acompanhar, na mesma velocidade, os avanços tecnológicos, a fim de possibilitar a proteção de interesses socialmente relevantes.

A internet, apesar de representar, para muitos, um avanço para a humanidade, também proporcionou o desenvolvimento de atividades ilícitas, seja com o envio de malwares, websites falsos, entre diversos outros crimes, e ainda dando coragem para cometer algum ilícito para aqueles que ainda não tinham cometido e que podem acreditar estarem se escondendo atrás de uma tela de computador. No entanto, não só informações confidenciais como senhas e códigos podem ser objeto de furto ou de interesse de terceiro. Informações como hábitos, costumes, gostos, sites que visitam com frequência, o que se pesquisa, entre outras navegações pela internet são extremamente valiosas para o mundo corporativo. Com tais informações se formam perfis de consumidores, classificando-os em grupos, de acordo com seus hábitos, faixa etária e gostos. Estas informações, muitas das vezes, estarão vinculadas a intimidade e privacidade do consumidor e poderá ser objeto de coleta, cadastramento e gerenciamento sem o seu consentimento e muito menos autorização, embora a intimidade e a privacidade sejam garantias básicas previstas na Constituição Federal, em seu artigo $5^{\circ}$, incisos X e XII.

Em tema de proteção de dados dos consumidores, Liliana Minardi Paesani cita a experiência europeia sobre um modelo de tratamento de dados pessoais que transpõe os

${ }^{14}$ LISBOA, Roberto Senise. Direito na sociedade da informação. Revista dos Tribunais, ano 95, vol.847, maio 2006, p. 91/92. 
ordenamentos jurídicos nacionais e se baseia na autodeterminação informativa que atribui a cada pessoa o poder de decidir sobre o uso de determinadas informações privadas, ou seja, necessário o consentimento do interessado, e acrescenta:

Explica Rodotà que, para impedir a violação desses direitos, se torna necessário introduzir procedimento de 'avaliação de impacto sobre a privacidade' semelhante àquele já estabelecido para avaliar o impacto ambiental. A poluição das liberdades civis não é menos importante que a poluição do meio ambiente ${ }^{15}$.

E conclui Liliana Minardi Paesani ${ }^{16}$ que a autodeterminação informativa não é absoluta, pois baseada está no princípio da finalidade que prevê situações de total indisponibilidade, onde nem mesmo o titular do direito poderá fornecer autorização para o uso de determinados dados, os chamados dados sensíveis, relacionados à esfera mais íntima da pessoa humana, capazes de violar sua dignidade.

Sobre o tema de proteção do consumidor na sociedade da informação, Roberto Senise Lisboa $^{17}$ cita a Resolução de 19.1.1999, sobre "aspectos relativos ao consumidor na sociedade da informação" (1999/C 23/01) do Conselho da União Europeia, que busca harmonizar e orientar a uniformização da legislação local, com a finalidade de facilitar a circulação de mercadoria através de contratos eletrônicos, mas sem perder de vista a proteção do consumidor e a facilitação de acesso à defesa dos seus direitos, acrescentando os riscos a que se expõem os consumidores. Pode-se afirmar que, independente das formas que as relações jurídicas venham a se firmar, seja através dos meios tradicionais de contrato escrito ou por meio eletrônico, o certo é que os direitos fundamentais e as garantias constitucionais devem guiar as regras contratuais. Toda e qualquer norma jurídica ou relação contratual, independente do meio de sua formalização, jamais poderia desconsiderar a dignidade da pessoa humana e as garantias básicas constitucionais, sendo que a defesa do consumidor se trata de uma garantia prevista no artigo $5^{\circ}$, inciso XXXII, da Constituição Federal, estabelecida como obrigação do Estado.

Luis Roberto Barroso sustenta que as normas constitucionais, seus princípios e garantias, deverão sempre refletir sobre a interpretação e aplicação das normas infraconstitucionais.

\footnotetext{
${ }^{15}$ PAESANI, Liliana Minardi. A evolução do direito digital: sistemas inteligentes, a Lei $n^{\circ} 12.737 / 2012$ e a privacidade. In: PAESANI, Liliana Minardi (Coord.). Direito na sociedade da informação III. São Paulo: Atlas, 2013, p.24-25.

16 Ibidem.

17 LISBOA, Roberto Senise. Proteção do consumidor na sociedade da informação. Revista de Direito Privado da Universidade Estadual de Londrina. Vol.2, $n^{\circ}$ 1, jan/abr 2009, p.16/17.
} 
Os valores, os fins públicos e os comportamentos contemplados nos princípios e regras da Constituição passam a condicionar a validade e o sentido de todas as normas do direito infraconstitucional. Como intuitivo, a constitucionalização repercute sobre a atuação dos três poderes, inclusive e notadamente nas suas relações com os particulares. Porém, mais original ainda: repercute, também, nas relações entre particulares. Veja-se como este processo, combinado com outras noções tradicionais, interfere com as esferas acima referidas ${ }^{18}$.

No campo do meio ambiente digital, cita-se Celso Antonio Pacheco Fiorillo.

[...] o direito à dignidade, de maneira geral e como princípio constitucional, impõe a defesa da integridade física e espiritual do homem como dimensão inalienável da sua individualidade autonomamente responsável: a garantia de identidade e integridade da pessoa pelo livre desenvolvimento da personalidade. Destarte, a proteção dos direitos fundamentais constitui corolário lógico do pilar constitucional da tutela da dignidade e referida tutela ganha especial relevo diante de novas violações a direitos que podem surgir no contexto de meio ambiente digital ${ }^{19}$.

Embora a livre iniciativa seja fundamento da República, conforme artigo $1^{\circ}$, inciso IV, e o artigo 170 determinar que a ordem econômica, fundada também na livre iniciativa, deve-se observar que a finalidade é assegurar a existência digna de todos, devendo, dentre outros, observar-se o princípio da defesa do consumidor (inciso $V$ do artigo 170), como deve ser ressaltada a inviolabilidade da intimidade, vida, honra e imagem das pessoas, como garantia constitucional (artigo $5^{\circ}$, inciso X), todos da Constituição Federal.

\section{ESTUDO DE CASO: RESOLUÇÃO RDC N54/2013 E IN N6/2014, DA ANVISA, EM CUMPRIMENTO À LEI N 11.903, DE 14 DE JANEIRO DE 2009}

Há muito que o mundo tem se deparado com um grave problema de saúde pública. A falsificação de medicamentos é uma realidade não só em países em desenvolvimento, mas também em países desenvolvidos, mal este de extrema gravidade, podendo causar danos irreversíveis aos consumidores que, em muitos casos, podem ser levados a óbito por terem necessitado do medicamento original e não o obtiveram, fazendo uso de medicamento falso que não gera efeito algum, ou pior, gera efeito maléfico.

\footnotetext{
${ }^{18}$ BARROSO, Luis Roberto. Neoconstitucionalismo e Constitucionalização do Direito - O triunfo tardio do direito constitucional no Brasil. Revista de Direito da Procuradoria Geral do Estado do Rio de Janeiro: 2006, p.149.

${ }^{19}$ FIORILLO, Celso Antonio Pacheco. Crimes no Meio Ambiente Digital. São Paulo: Saraiva 2013, p.38-39.
} 
A ANVISA - Agência Nacional de Vigilância Sanitária disponibiliza informações sobre os lotes de produtos falsificados no Brasil, conforme relação abaixo, que identifica os medicamentos falsificados no período de 2005 a $2009^{20}$.

Tabela 1. Relação de lotes de medicamentos falsificados.

\begin{tabular}{|c|c|c|c|c|c|c|}
\hline Produto & 2005 & 2006 & 2007 & 2008 & 2009 & $\begin{array}{c}\text { Total } \\
\text { medicamento }\end{array}$ \\
\hline Cialis (tadalafila) & 1 & 5 & 4 & 6 & 13 & 29 \\
\hline Deca Durabolin (decanoato de nandrolona). & & & & 1 & & 1 \\
\hline $\begin{array}{l}\text { Dibetam (fosfato dissódico de betametasona, } \\
\text { dipropionato de betametasona). }\end{array}$ & & & 1 & & & 1 \\
\hline $\begin{array}{l}\text { Durateston (isocaproato de testosterona, } \\
\text { decanoat de testosterona, fempropionato de } \\
\text { testosterona, propionato de testosterona). }\end{array}$ & & & & 4 & 1 & 5 \\
\hline Fluarix (vírus contra a gripe) & & 1 & & & & 1 \\
\hline Glivec (mesilato de imatinibe) & & & 1 & & & 1 \\
\hline Hemogenin (oximetolona) & & & & & 4 & 4 \\
\hline Levitra (cloridrato de vardenafila) & & & 1 & & & 1 \\
\hline Viagra (citrato de sildenafila) & & 8 & 2 & 1 & 2 & 13 \\
\hline Total anual & 1 & 14 & 9 & 12 & 20 & 56 \\
\hline
\end{tabular}

No Brasil, a falsificação de medicamento está tipificada como crime ${ }^{21}$ punido com pena de reclusão de 10 (dez) a 15 (quinze) anos, e multa, sendo que, a partir da lei $\mathrm{n}^{\circ}$ 9.695, de 20 de agosto de 1998, que alterou a lei $\mathrm{n}^{\circ}$ 8.072, de 25 de julho de 1990, que trata de crimes hediondos, fez constar deste rol a "falsificação, corrupção, adulteração ou alteração de produto

\footnotetext{
${ }^{20}$ BRASIL. Agência Nacional de Vigiência Sanitária. Relação de lotes de medicamentos falsificados disponível em: <http://www.anvisa.gov.br/medicamentos/falsificados/index.htm>. Acesso em: $16 \mathrm{abr}$. 2015.

${ }^{21}$ Decreto-Lei 2.848, de 7 dez. 1940, Art. 273 - Falsificar, corromper, adulterar ou alterar produto destinado a fins terapêuticos ou medicinais: Pena - reclusão, de 10 (dez) a 15 (quinze) anos, e multa. BRASIL. Código Penal. Decreto-Lei, de 7 dez. 1940. Diário Oficial da República Federativa do Brasil, DF, 31 dez. 1940. Disponível em: <http://www.planalto.gov.br/ccivil_03/decretolei/Del2848compilado.htm>. Acesso em: 16 abr. 2015.
} 
destinado a fins terapêuticos ou medicinais"22. Entretanto, a gravidade na punição para a conduta não tem se demonstrado eficaz para impedir a prática, não evitando o risco ao consumidor final.

O Sistema Nacional de Controle de Medicamentos foi instituído pela lei $\mathrm{n}^{\circ} 11.903$, de 14 de janeiro de 2009, com o objetivo de combater a falsificação e adulteração de medicamentos, entre outros. Com a implantação do sistema de rastreabilidade e identificador único de medicamento (IUM), cada unidade do produto terá uma identificação e caso outra unidade exista com igual identificação, esta provavelmente será falsa. A lei deferiu competência ao órgão de vigilância sanitária federal, no caso a ANVISA - Agência Nacional de Vigilância Sanitária, quanto à incumbência de regulamentar todo o mecanismo e procedimento de fiscalização e rastreabilidade de medicamentos. Em 2013, a ANVISA - Agência Nacional de Vigilância Sanitária realizou a Consulta Pública $n^{\circ}$ 10/2013, para participação da sociedade em geral, recebendo contribuições no período de 10/04/2013 a 09/05/2013, resultando na participação de profissionais da saúde, entidades de classe, da indústria farmacêutica, de empresas de tecnologia da informação, do varejo farmacêutico, entre outros. Em decorrência do resultado da consulta pública e das contribuições oferecidas foi editada a Resolução da Diretoria Colegiada $n^{\circ}$ 54 - ANVISA que estabeleceu, entre outras disposições, que a rastreabilidade de medicamentos será realizada "por meio de tecnologia de captura, armazenamento e transmissão eletrônica de dados, em toda a cadeia dos produtos farmacêuticos" (artigo $1^{\circ}$ ). Em seguida, foi editada a Instrução Normativa ${ }^{\circ}$ 6, de 18 de agosto de 2014, que instituiu o regramento para implantação da rastreabilidade de medicamentos no território nacional. Possuindo o sistema de rastreabilidade como uma de suas finalidades impedir a pirataria de medicamentos, o comércio irregular de medicamentos resultantes do desvio de carga, o controle da qualidade de tais produtos até que chegue ao consumidor final, bem como evitar a prescrição comercial, ou seja, a venda de receitas médicas e restou estabelecido pela ANVISA - Agência Nacional de Vigilância Sanitária que cada detentor do registro do medicamento (indústria farmacêutica) desenvolverá sistema próprio de captura de dados de controle e rastreabilidade dos produtos que fabrica, competindo aos demais elos da cadeia de fornecimento (atacadistas e varejistas) alimentar, em

\footnotetext{
22 Lei 8.072, de 25 jul. 1990, Art. $1^{\circ}$ São considerados hediondos os seguintes crimes, todos tipificados no Decreto-Lei no 2.848, de 7 de dezembro de 1940 - Código Penal, consumados ou tentados: ...VII-B falsificação, corrupção, adulteração ou alteração de produto destinado a fins terapêuticos ou medicinais. BRASIL. Lei 8.072. Lei dos crimes hediondos. Diário Oficial da República Federativa do Brasil, DF, 27 jul. 1990. Disponível em: < http://www.planalto.gov.br/ccivil_03/LEIS/L8072.htm>. Acesso em: 16 abr. 2015.
} 
tempo real, o sistema ora desenvolvido com informações sobre sua operação, indicando quando, quanto e de quem recebeu mercadoria e quando, quanto e para quem a enviou.

Questão importante quanto ao Sistema Nacional de Controle de Medicamentos é que a concentração da informação oriunda do sistema de rastreabilidade será armazenada em banco de dados de propriedade da indústria farmacêutica, que disporá de informações empresariais sensíveis aos negócios dos demais elos da cadeia de fornecimento, além de informações íntimas dos consumidores usuários dos medicamentos, quadro este estabelecido pelo artigo $4^{\circ}$ da Instrução Normativa $\mathrm{n}^{\circ}$ 6, de 18 de agosto de 2014, da Agência Nacional de Vigilância Sanitária ${ }^{23}$, vinculada ao Ministério da Saúde.

A regulamentação do Sistema Nacional de Controle de Medicamentos estabelece que as informações das relações comerciais de toda a cadeia de fornecimento deverão ser concentradas nas mãos de alguns dos atores da relação empresarial, quais sejam, as indústrias farmacêuticas e os distribuidores (atacadistas). Os demais integrantes do elo comercial deverão fornecer todas as informações à indústria farmacêutica e ao elo precedente da cadeia de fornecedor, devendo informar quantidade de produtos que possui em estoque, para quem e quando vendeu, entre outras informações sensíveis, para que estes formem um banco de dados que ficará de sua posse para quando o ente estatal consultar ou quiser consultar (no caso, a ANVISA - Agência Nacional de Vigilância Sanitária). Deverá ser informado, ainda, o prescritor do medicamento (nome e registro no conselho profissional de quem prescreveu, quanto e quando prescreveu e para quem prescreveu), seja médico, odontólogo ou veterinário. Além de informações sensíveis à atividade econômica de outros atores da relação mercantil (varejistas). O Sistema Nacional de Controle de Medicamentos estabelece que informações como dados do consumidor sejam também armazenados pela indústria farmacêutica.

Sendo a informação sobre custos, logística, estoque e meios de produção passível de valoração, também o é para utilização estratégica em negócios empresariais. Com informações sobre custos, operações, logística e estoque, as negociações entre indústria farmacêutica e comércio varejista poderão sofrer impactos negativos e acarretar forte desequilíbrio negocial, que, por certo, refletirá no consumidor final. Como exemplo, tem-se a hipótese de negociação

\footnotetext{
${ }^{23}$ Instrução Normativa ${ }^{\circ}$ 6, de 18 de agosto de 2014, Art. $4^{\circ}$. Os eventos ocorridos ao longo da cadeia de medicamentos deverão ser transmitidos em tempo real ao detentor do registro do produto e ao elo precedente da cadeia no momento em que forem registrados no banco de dados pelo responsável, conforme o disposto nos artigos 16, 17 e 18 da RDC n 54/2013. Revogada em: 27 out. 2015.
} 
entre indústria farmacêutica e um varejista, sendo que a indústria saberá quanto de estoque de determinado produto o varejista possui, se necessita com urgência ou não do medicamento, como também poderá identificar um potencial cliente de um atacadista e passar a tratar diretamente com ele, suprimindo a intervenção do atacadista. Da mesma forma, informações sobre utilização de determinados medicamentos, quantidade, periodicidade, em relação aos consumidores na posse das indústrias farmacêuticas, permitirão o direcionamento de marketing agressivo e, principalmente, invasivo na vida privada dos consumidores, violando a sua intimidade. A prática, ainda, poderá possibilitar maior assédio ao corpo médico [incluídos odontólogos e veterinários] por parte da indústria, que poderá acompanhar a quantidade de medicamentos que determinado profissional prescreve e até enviar brindes para os "recordistas" e determinar o aumento de visitas de propagandistas para os que não estejam com números “aceitáveis” de prescrição. Em depoimento do dia 25 de janeiro de 2000, para a Comissão Parlamentar de Inquérito dos Medicamentos (CPI dos Medicamentos) ${ }^{24}$, tendo como relator o Deputado Ney Lopes, o Sr. Edson de Oliveira Andrade, então presidente do Conselho Federal de Medicina, afirmou:

[...] existe, com certeza, uma influência muito grande, na indústria farmacêutica, na prática profissional; isso se dá, é uma realidade; isso se dá[...] na simples visita [...] num consultório; isso se dá no patrocínio do congresso; talvez a grande influência que ocorra na prática profissional não se dê nessa visita rotineira de consultórios, aquela entrega de propaganda, de impressos; ela se dá, basicamente, na construção do pensar médico [...] dentro dos congressos.

Em pesquisa realizada pelo Conselho Regional de Medicina do Estado de São Paulo ${ }^{25}$, em janeiro de 2010, foram publicados os seguintes resultados em relação à influência e assédio da indústria farmacêutica sobre a classe médica: 93\% dos médicos recebem brindes e benefícios das empresas farmacêuticas e de equipamentos; $80 \%$ dos médicos recebem visitas de representantes da indústria de medicamentos; $74 \%$ dos médicos declaram que os benefícios das indústrias se iniciam na graduação, durante os 6 (seis) anos do curso de Medicina; 33\% dos médicos souberam

24 BRASIL. Câmara dos Deputados. Relatório final da Comissão Parlamentar de Inquérito dos Medicamentos, de 30 de maio de 2000, relator Deputado Federal Ney Lopes.

Disponível em http://www2.camara.leg.br/atividade-legislativa/comissoes/comissoestemporarias/parlamentar-de-inquerito/51-legislatura/cpimedic/relatfinal.html. Acesso em 25 jan. 2016.

${ }^{25}$ CONSELHO REGIONAL DE MEDICINA DO ESTADO DE SÃO PAULO. Pesquisa sobre o relacionamento dos médicos paulistas com a indústria de medicamentos, órteses, próteses e equipamentos médicohospitalares São Paulo, realizado pelo Datafolha Instituto de Pesquisas entre dezembro de 2009 e janeiro de 2010. Disponível em <http://www.cremesp.org.br/?siteAcao=Jornal\&id=1308>. Acesso em 25 jan. 2016. 
ou presenciaram casos de pressão da indústria sobre médicos ou alguma parceria comercial considerada inadequada (recebimento de comissões por procedimento, medicamentos etc., ou indicação destes). Entretanto, o problema do assédio das indústrias farmacêuticas sobre classe médica, influenciando na decisão desta sobre a saúde dos seus pacientes, onde o lucro estaria acima da cura, é um problema global. Em estudo Mônica Teixeira ${ }^{26}$ menciona questionamentos realizados pelo senador americano Herb Kohl, em audiência da Comissão Especial do Senado Americano sobre o Envelhecimento, em 29 de julho de 2009, explanando sua preocupação com o envolvimento cada vez maior no financiamento da educação médica, acrescentando ser caro oferecer formação e acesso às inovações médicas mais recentes, apoio financeiro este justificado ou permitido pelos custos crescentes que enfrentam os hospitais de ensino e escolas médicas, e alertando que grandes corporações não gastam somas significativas sem ao menos pensarem que irão obter retorno ou alguma vantagem em troca, pois são assim que os negócios funcionam, e conclui:

Isto nos leva à questão crucial da audiência de hoje. A indústria de medicamentos e de dispositivos está obtendo retorno pelo seu investimento anual de US\$ 1 bilhão em educação médica? Os programas financiados pela indústria permanecem fiéis à missão de fornecer educação e pesquisa imparciais, ou ao invés disso servem à promoção dos últimos produtos da indústria?

Nessa mesma audiência no Senado americano, foi ouvido o Sr. Steven E. Nissen ${ }^{27}$, presidente do Departamento de Medicina Cardiovascular na Clínica Cleveland e ex-presidente do Colégio Americano de Cardiologia, que se manifestou no sentido de que a Educação Médica Continuada, conhecida como CME, foi pensada para servir como principal meio de atualização dos conhecimentos médicos, mantendo a qualidade dos serviços prestados à população, sendo certo que alguns Estados Federativos americanos exigem um número mínimo de créditos de CME como condição para continuidade da licença para clinicar ou exercer a enfermagem, e acrescentou:

Idealmente, CME deveria oferecer educação equilibrada e baseada em ciência para melhorar a qualidade dos cuidados de saúde. Ao invés disso, a CME se

\footnotetext{
26 TEIXEIRA, M. A bilionária indústria da educação médica continuada nos EUA: mais uma forma de interferência das empresas na relação médico-paciente. Revista Latinoamericana de Psicopatologia Fundamental. São Paulo, v. 12, n. 4, p. 731-742, dez. 2009, p.733

27 TEIXEIRA, M. A bilionária indústria da educação médica continuada nos EUA: mais uma forma de interferência das empresas na relação médico-paciente. Revista Latinoamericana de Psicopatologia Fundamental. São Paulo, v. 12, n. 4, p. 731-742, dez. 2009, p.738
} 
transformou em um veículo insidioso para a promoção agressiva de drogas e dispositivos médicos. Estranhamente, $50 \%$ do financiamento de CME, cerca de US\$ 1,2 bilhões, vem de companhias que comercializam medicamentos $\mathrm{e}$ dispositivos médicos. Essencialmente, as divisões de marketing dessas empresas agora dominam uma proporção substancial da educação dos médicos. CME evoluiu largamente para marketing, inteligentemente disfarçado em educação.

A indústria farmacêutica investe de forma agressiva em marketing, destinando até $20 \%$ do seu faturamento para tal área ${ }^{28}$, verba superior até o dobro do investido em pesquisas de novos produtos e tais dados demonstram o perigo da concentração nas mãos da indústria farmacêutica de informações sensíveis do sistema de rastreabilidade de medicamentos, seja quanto à logística do comércio varejista de medicamentos (desequilíbrio nas negociações), seja sobre informações relativas aos profissionais de saúde (marketing agressivo) e seja ainda quanto à privacidade dos consumidores.

Um dos elos da cadeia de fornecimento, o comércio varejista, através de uma de suas associações (ABRAFARMA - Associação Brasileira de Redes de Farmácia e Drogarias), sentindo-se lesada pela regra estabelecida pela RDC $n^{\circ}$ 54/2013 e IN n 06/2014, propôs em 17 de dezembro de 2014, ação judicial de $n^{\circ}$ 0092563-42.2014.4.01.3400, distribuída para a $3^{\text {a }}$ Vara Federal da Seção Judiciária do Distrito Federal, em face da ANVISA - Agência Nacional de Vigilância Sanitária, impugnando, em benefício de suas associadas, a obrigatoriedade de fornecer informações sensíveis das suas operações comerciais para a indústria farmacêutica, objetivando, ao final, livrar suas associadas da obrigação de atender tais normas sanitárias e, em 8 de setembro de 2015, foi deferida tutela antecipada pelo MM. Juiz Federal Dr. Bruno Anderson Santos da Silva, desobrigando as associadas da ABRAFARMA a cumprir o estabelecido na RDC e IN impugnadas, no que se refere ao fornecimento de informações sobre suas atividades mercantis à indústria farmacêutica.

\section{CONCLUSÃO}

O objetivo foi trazer à discussão o valor econômico da informação e sua utilização nas operações empresariais. A informação sempre foi de suma importância para as sociedades e o seu domínio com armazenamento e tratamento com as técnicas introduzidas pelas novas

${ }^{28}$ BRASIL. Câmara dos Deputados. Aprovação do relatório da Comissão Parlamentar de Inquérito. Disponível em: http: / /www.camara.gov.br/proposicoesWeb/prop_mostrarintegra?codteor=1244078\&file name=Dossie+-PRC+177/1980+CPIIF. Acesso em 25 jan. 2016, p 202 


\section{(1)

A INFORMAÇÃO COMO PRODUTO E A PROTEÇÃO DO CONSUMIDOR NA SOCIEDADE DA INFORMAÇẪO: ESTUDO DE CASO

ROGER DA SiLVA MOREIRA SOARES MARCO ANTÔNIO BARBOSA

tecnologias da informação (TIC) exacerbou essa importância provocando a atual revolução informacional na qual se vive e onde novas relações jurídicas também surgem repercutindo sobre direitos e garantias existentes e, embora a informação seja de extrema valia, as novas estratégias do mercado parecem ameaçar as normas jurídicas e as garantias constitucionais dos cidadãos em geral e dos consumidores em particular, a exemplo do que ocorre com as informações e dados sensíveis desses últimos, especificamente diante da proteção ou vulnerabilidade de sua intimidade e privacidade, de modo que o controle e a regulação do uso de informações que circulam pela rede mundial de computadores ainda exigem maior atenção.

A demanda judicial movida pela ABRAFARMA - Associação Brasileira de Redes de Farmácia e Drogarias reflete as preocupações de um dos atores da cadeia de fornecimento de medicamentos (comércio varejista), quanto ao prejuízo que será gerado em suas atividades econômicas. Entretanto, nítido também é o prejuízo que poderá ser causado ao consumidor final, seja de forma direta ou indireta, econômica (influência no preço final do medicamento pelo desequilíbrio nas negociações entre indústria, atacadista e varejista) ou em sua intimidade (direcionamento de marketing agressivo contra si), eis que informações sensíveis relativas a sua intimidade passam a ser concentradas em bancos de dados pertencentes às corporações com evidente objetivo de lucro, o que leva à conclusão de que o regramento de implantação do Sistema Nacional de Controle de Medicamentos, da forma que se encontra, deve ser revisto, a fim de se evitar violações aos direitos mais basilares garantidos pela Constituição Federal.

\section{REFERÊNCIAS}

BARRETO JÚNIOR, Irineu Francisco. Atualidade do conceito de sociedade da informação para pesquisa jurídica. In: PAESANI, Liliana Minardi (Coord.). Direito na sociedade da informação. São Paulo: Atlas, 2007, p. 113 a 130.

BARROSO, Luis Roberto. NEOCONSTITUCIONALISMO E CONSTITUCIONALIZAÇÃO DO DIREITO - O triunfo tardio do direito constitucional no Brasil. Revista de Direito da Procuradoria Geral do Estado do Rio de Janeiro: 2006.

BRASIL. Agência Nacional de Vigilância Sanitária. Resolução. Instrução Normativa $n^{\circ}$ 6, de 18 de agosto de 2014. Dispõe sobre a especificação da interface entre os detentores de registro de medicamentos e a Agência Nacional de Vigilância Sanitária - Anvisa para a operacionalização do Sistema Nacional de Controle de Medicamentos (SNCM), e dá outras providências. Disponível em: <http://portal.anvisa.gov.br/wps/wcm/connect/d256a380453f0b2 bbc5afca5af521445/int0006_18_09_2014.pdf?MOD=AJPERES>. Acesso em: 15 dez. 2015. 
. Agência Nacional de Vigilância Sanitária. Resolução. Resolução da Diretoria Colegiada $\mathrm{n}^{\circ}$ 54, de 10 de dezembro de 2013. Dispõe sobre a implantação do sistema nacional de controle de medicamentos e os mecanismos e procedimentos para rastreamento de medicamentos na cadeia dos produtos farmacêuticos e dá outras providências. Disponível em: <http://portal.anvisa.gov.br/wps/wcm/connect/c3d2028043c137b784beeee175024b76/rdc0054 _10_12_2013.pdf?MOD=AJPERES>. Acesso em: $15 \mathrm{dez} .2015$.

. Agência Nacional de Vigiência Sanitária. Relação de lotes de medicamentos falsificados disponível em: <http://www.anvisa.gov.br/medicamentos/falsificados/index.htm>. Acesso em 16 abr. 2015.

. Constituição da República Federativa do Brasil de 1988. Diário Oficial da República Federativa do Brasil, Brasília, DF, 5 out. 1988.

<http://www.planalto.gov.br/ccivil_03/constituicao/ConstituicaoCompilado.htm>. Acesso em 15 dez. 2015.

. Câmara dos Deputados. Aprovação do relatório da Comissão Parlamentar de Inquérito. Disponível em:

<http://www.camara.gov.br/proposicoesWeb/prop_mostrarintegra?codteor $=1244078$ \&filename $=$ Dossie+-PRC+177/1980+CPIIF>. Acesso em 25 jan. 2016.

. Câmara dos Deputados. Relatório final da Comissão Parlamentar de Inquérito dos Medicamentos, de 30 de maio de 2000, relator Deputado Federal Ney Lopes.

Disponível em: <http://www2.camara.leg.br/atividade-legislativa/comissoes/comissoestemporarias/parlamentar-de-inquerito/51-legislatura/cpimedic/relatfinal.html>. Acesso em 25 jan. 2016.

. Lei 8.072. Lei dos crimes hediondos. Diário Oficial da República Federativa do Brasil, DF, 27 jul. 1990. Disponível em: <http://www.planalto.gov.br/ccivil_03/LEIS/L8072.htm>. Acesso em: 16 abr. 2015.

. Código Penal. Decreto-Lei, de 7 dez. 1940. Diário Oficial da República Federativa do Brasil, DF, 31 dez. 1940. Disponível em: <http://www.planalto.gov.br/ccivil_03/decretolei/Del2848compilado.htm>. Acesso em: 16 abr. 2015.

BURKE, Peter. Uma História Social do Conhecimento: de Gutenberg a Diderot. Rio de Janeiro: Jorge Zahar, 2003.

CASTELLS, Manuel. A sociedade em rede, vol.1, $8^{\text {a }}$ ed., São Paulo: Paz e Terra, 1999.

CONSELHO REGIONAL DE MEDICINA DO ESTADO DE SÃO PAULO. Pesquisa sobre o relacionamento dos médicos paulistas com a indústria de medicamentos, órteses, próteses e equipamentos médico-hospitalares São Paulo, realizado pelo Datafolha Instituto de Pesquisas entre dezembro de 2009 e janeiro de 2010. Disponível em <http://www.cremesp.org.br/?siteAcao=Jornal\&id=1308>. Acesso em: 25 jan. 2016.

FIORILLO, Celso Antonio Pacheco. Crimes no Meio Ambiente Digital. São Paulo: Saraiva, 2013. 
LIPOVETSKY, Gilles. A felicidade paradoxal: Ensaio sobre a sociedade de hiperconsumo. São Paulo: Companhia das Letras, 2007.

LISBOA, Roberto Senise. Direito na sociedade da informação. Revista dos Tribunais, ano 95, vol.847, maio 2006.

- Proteção do consumidor na sociedade da informação. Revista de Direito Privado da Universidade Estadual de Londrina. Vol.2, n 1, jan/abr 2009.

PAESANI, Liliana Minardi. A evolução do direito digital: sistemas inteligentes, a Lei ${ }^{\circ}$ 12.737/2012 e a privacidade. In: PAESANI, Liliana Minardi (Coord.). Direito na sociedade da informação III. São Paulo: Atlas, 2013, p. 23 a 32.

. Direito de informática, 10ª ed., São Paulo: Atlas, 2015.

SHIRLEY, Robert Weaver. Antropologia Jurídica. São Paulo: Saraiva, 1987.

SIQUEIRA JUNIOR, Paulo Hamilton. A nova ordem constitucional. In: PAESANI, Liliana Minardi (Coord.). Direito na sociedade da informação III. São Paulo: Atlas, 2013, p. 193 a 226.

SIMÃO FILHO, Adalberto. Estabelecimento empresarial digital: natureza, elementos, atributos e valoração. In: PAESANI, Liliana Minardi (Coord.). Direito na sociedade da informação III. São Paulo: Atlas, 2013, p. 159 a 174.

TEIXEIRA, Mônica. A bilionária indústria da educação médica continuada nos EUA: mais uma forma de interferência das empresas na relação médico-paciente. Revista Latinoamericana de Psicopatologia Fundamental, São Paulo, v. 12, n. 4, dez. 2009, p. 731-742. 